Original Research Paper

\title{
Modelling and Assessment of Effect of Operation Parameters on Gas Turbine Power Plant Performance using First and Second Laws of Thermodynamics
}

\author{
${ }^{1}$ Sunday Olayinka Oyedepo, ${ }^{2}$ Richard Olayiwola Fagbenle and ${ }^{3}$ Samuel Sunday Adefila \\ ${ }^{I}$ Department of Mechanical Engineering, Covenant University, Ota, Nigeria \\ ${ }^{2}$ Department of Mechanical Engineering, University of Ibadan, Nigeria \\ ${ }^{3}$ Department of Chemical Engineering, Covenant University, Ota, Nigeria
}

Article history

Received: 17-11-2016

Revised: 02-12-2016

Accepted: 20-04-2017

Corresponding Author: Sunday Olayinka Oyedepo

Department of Mechanical

Engineering, Covenant

University, Ota, Nigeria

Email:

Sunday.oyedepo@covenantuni versity.edu.com

\begin{abstract}
In this study, modelling of gas turbine engine performance is carried out using thermodynamics relations. The model reveals that the influence of operation parameters such as compression ratio, turbine inlet temperature and ambient temperature has significant effect on the performance of gas turbine engine. Energy and exergy analyses were conducted to evaluate the performance of the selected power plant and to assess the effect of operation parameters on energy loss and exergy destruction in the plant. Energy analysis shows that the turbine has the highest proportion of energy loss (31.98\%) in the plant. The exergy analysis results reveal that the combustion chamber is the most exergy destructive component compared to other cycle components. Thermal efficiency of the plant is as low as $36.68 \%$ while the total efficiency defect and overall exergetic efficiency of the power plant are 40.46 and $19.06 \%$, respectively.
\end{abstract}

Keywords: Model, GTIT, Exergetic Efficiency, Ambient Temperature, Gas Turbine Engine, Simulation

\section{Introduction}

Gas turbines have come to play a significant role in energy conversion systems due to its multi-fuel capability, compact size and low environmental impact and reduced operational and maintenance cost. Growing demand of power and degradation of environment have made gas turbine power plants of scientific interest for the efficient utilization of energy resources (Ghazikhani et al., 2014; Reddy et al., 2013).

A gas turbine converts heat energy of fuel into useful work. It is different from a steam turbine in the sense that there is no change of phase in the working fluid used in a gas turbine, whereas there is change of phase in working fluid used in a steam turbine. Gas turbines are steady flow power machines in which a gas (usually air) is compressed, heated and expanded for the purpose of generating power. The term turbine is the component which delivers power from the gas as it expands; it is also called an expander and it is also refer to a complete power machine (Kreith and Goswaini, 2005). Gas turbines utilized in electric-power generation are manufactured in two classes which are heavy-duty and aero derivative. These two classes of turbines have different performance, cost, partial load modelling, as well as different performance variations with the ambient temperature (Chaker et al., 2003).

Gas turbines (GTs) have been used for electricity generation in most countries around the world. In the past, their use has generally been limited to generate electricity in periods of peak electricity demand. Gas turbines are ideal for this application as they can be started and stopped quickly, enabling them to be brought into service as required to meet energy demand peaks (Jaber et al., 2007). However, due to availability of natural gas at relatively cheap prices compared to distillate fuels, many countries around the world, e.g Nigeria, use large conventional GTs as base load units (Oyedepo and Kilanko, 2014).

In gas turbines, since the air for combustion is taken directly from the environment, their performance is strongly affected by both external factors (ambient temperature and relative humidity) and internal factors (components efficiencies, turbine inlet temperature, compression pressure ratio etc). Efficiency and electricpower output of gas turbines vary according to the 
ambient conditions (Jaber et al., 2007). The amount of these variations greatly affects electricity production, fuel consumption and plant incomes (Erdem and Sevilgen, 2006). Power rating can drop by as much as 20 to $30 \%$, with respect to International Standard Organization (ISO) design conditions, when ambient temperature reaches 35 to $45^{\circ} \mathrm{C}$ (Mahmoudi et al., 2009; Guinee, 2001). One way of restoring operating conditions is to add an air cooler at the compressor inlet (Sadrameli and Goswami, 2007; (Oyedepo and Kilanko, 2014). The air cooling system serves to raise the gas turbine performance to peak power levels during the warmer months when the high atmospheric temperature causes the turbine to work at off-design conditions with reduced power output (Kakaras et al., 2004; Kamal and Zubair, 2006; Khaliq et al., 2009). From external factors point of view, the effect of Turbine Inlet Temperature (TIT) is predominant. According to Rahman et al. (2011a; Ameri et al., 2007), for every $5-6^{\circ} \mathrm{C}$ increase in TIT, the power output increases approximately $10 \%$ and gives about $1.5 \%$ increase in efficiency. Overall efficiency of the gas turbine cycle depends primarily upon the pressure ratio of the compressor.

For comparative purpose, the ISO has established standard conditions which are universally accepted and used for gas turbine performance. Standard air conditions in gas turbine designing at sea level is $25^{\circ} \mathrm{C}$ temperature and $60 \%$ relative humidity (Hall et al., 1994). Power output while operating in these conditions is termed as the standard power. Analyses performed by previous researchers showed that operating below this temperature improved performance and operating above this temperature reduced performance (Bassily, 2001; Gareta et al., 2005; Kopac and Hilalci, 2007).

The performance of thermal power plant operating at off design, from the thermodynamics viewpoint, can be evaluated by the first (energy) and second (exergy) laws. The energy based criteria provides a quantitative interpretation of the thermodynamics analysis (Egware and Obanor, 2013a), while the exergy based criteria is associated to qualitative information, describing the system in its critical points by the irreversibilities (losses) occurring in the process (Lior and Zhang, 2007). Hence, exergy-based criteria are considered more appropriate for assessing energy system performance as they account better for use of energy resources and give much better guidance for system improvement. They also can be converted to exergy cost efficiencies if the exergy values of the useful outputs and paid inputs can be rationally priced.

In recent years, numerous and extensive researches have been conducted to evaluate thermal power systems from both energy and exergy analyses point of view (Bilgen, 2000; Ray et al., 2007; Khaldi and Adouane, 2011; Chen et al., 2014; Soltani et al., 2015; Martin et al., 2016; Ganapathy et al., 2009; Egware and Obanor, 2013b; Ahmadi et al., 2011). Table 1 shows the brief summary of studies on proportion of exergy destruction in various components of thermal plant by different authors and year of study.

This does in no way claim to be a complete account of all the contributions to exergy analyses of power cycles from inception to the present time, rather Table 1 presents some highlights on the journey so far.

The prime objectives of this study are:

- To model gas turbine engine and investigate the effect of variation of operation conditions on performance of gas turbine engine

- To evaluate performance of selected gas turbine power plant using first and second laws of thermodynamics

Table 1. Summary of studies on proportion of exergy destruction in various components of thermal plant by different authors and year of study

\begin{tabular}{|c|c|c|c|c|}
\hline Author (s) & System studied & $\begin{array}{l}\text { Component having } \\
\text { highest exergy destruction }\end{array}$ & $\begin{array}{l}\text { Component having highest } \\
\text { exergy destruction cost }\end{array}$ & $\begin{array}{l}\text { Year of } \\
\text { Study }\end{array}$ \\
\hline Habib & Steam turbine Co-generation plant & Boiler & Boiler & 1994 \\
\hline Osman et al. & Co-generation plant & Boiler (70-76\%) & Boiler & 2006 \\
\hline Ibrahim-Bin et al. & Steam turbine plant & Boiler & Boiler & 2001 \\
\hline Ofodu and Abam & Gas turbine plant & Turbine & Turbine & 2002 \\
\hline Khaliq and Kaushik & Combined power plant & Combustor $(50 \%)$ & Combustor & 2004 \\
\hline Suresh et al. & Gas turbine plant & Combustor & Combustor & $2006 a$ \\
\hline Suresh et al. & Coal-based thermal plant & $\begin{array}{l}\text { Coal combustor and } \\
\text { Steam generator }\end{array}$ & $\begin{array}{l}\text { Coal combustor and } \\
\text { Steam generator }\end{array}$ & $2006 b$ \\
\hline Fagbenle et al. & $\begin{array}{l}\text { Bio gas-fired gasification steam } \\
\text { injected gas turbine (BIG/STIG) }\end{array}$ & Combustor $(79 \%)$ & Combustor & 2007 \\
\hline Sanjay et al. & Hybrid gas turbine plant & Combustor $(27 \%)$ & Combustor & 2009 \\
\hline Aljund & Steam turbine plant & Boiler $(77 \%)$ & Boiler & 2009 \\
\hline Rajkumar and Ashok & Steam turbine plant & Boiler (57.8\%) & Boiler & 2009 \\
\hline Balkrishna & Captive steam plant & Boiler $(75 \%)$ & Boiler & 2009 \\
\hline Ighodaro and Aburime & Gas turbine plant & Combustion chamber $(56 \%)$ & Combustion chamber & 2011 \\
\hline Abam and Moses & Gas turbine plant & Combustion chamber & Combustion chamber & 2011 \\
\hline Obodeh and Ugwuoke & Steam turbine plant & Boiler & Boiler & 2013 \\
\hline
\end{tabular}




\section{Materials and Methods}

\section{Data Collection}

In this study, AES barges gas turbine plant unit PB204 with installed capacity of $31.5 \mathrm{MW}$ was selected for study. The plant is situated on the lagoon jetty, at the PHCN Egbin Thermal Station premise, in Ijede, a suburb of Ikorodu Town in Lagos, Nigeria. Operating data for the gas turbine unit were collected from the daily turbine control log sheet for a period of five years (2006-2010). The daily average operating variables were statistically analyzed and mean values were computed for the period of January to December, followed by an overall average. A summary of the operating parameters of the PB204 unit used for this study is presented in Table 2. The analysis of the plant was divided into different control volumes and performance of the plant was estimated using componentwise modeling. Mass, energy conservation laws and exergy balance were applied to each component and the performance of the plant was determined for the system.

\section{Gas Turbine Plant Simulation with MATLAB R2010a}

Gas turbine engine was simulated using MATLAB codes developed by the authors. This was done to investigate the effect of variation of operating conditions (compression ratio, turbine inlet temperature and ambient temperature) on performance of gas turbine engine. Gas turbine cycle was modelled using each component (compressor, combustion chamber and turbine) and governing thermodynamics and chemical relations. Cumulative performance indices such as thermal efficiency, power output, specific fuel consumption, heat supplied and net-work output were calculated.

The gas turbine engine model developed in this study was based on the following basic thermodynamics assumptions:

- All the processes were considered steady state

- The principle of ideal-gas mixture was applied for the air and combustion products

- The dead/reference state condition is $\mathrm{P} 0=1.013$ bar and $\mathrm{T} 0=298.15 \mathrm{~K}$

- The isentropic efficiency of compressor and turbine are assumed to be constant and equal to 0.85 and 0.87 respectively

- In the combustion chamber (CC), $2 \%$ pressure drop was assumed

- Combustion efficiency and mechanical efficiency were assumed to be constant and equal to 0.98 and 0.99 respectively

Table 2. Average operating data for the selected gas turbine power plant

\begin{tabular}{llr}
\hline Operating parameters & Unit & Value \\
\hline Ambient Temperature, $\mathrm{T}_{1}$ & $\mathrm{~K}$ & 303.63 \\
Compressor outlet temperature, $\mathrm{T}_{2}$ & $\mathrm{~K}$ & 622.31 \\
Turbine inlet temperature, $\mathrm{T}_{3}$ & $\mathrm{~K}$ & 1218.62 \\
Turbine outlet temperature, $\mathrm{T}_{4}$ & $\mathrm{~K}$ & 750.00 \\
Exhaust gas temperature, $\mathrm{T}_{\mathrm{exh}}$ & $\mathrm{K}$ & 715.00 \\
Compressor inlet pressure, $\mathrm{P}_{1}$ & $\mathrm{bar}$ & 1.01 \\
Compressor outlet pressure, $\mathrm{P}_{2}$ & $\mathrm{bar}$ & 9.80 \\
Pressure ratio & - & $\mathrm{kg} / \mathrm{s}$ \\
Mass flow rate of fuel & $\mathrm{kg} / \mathrm{s}$ & 9.67 \\
Inlet mass flow rate of air & $\mathrm{MW}$ & 2.58 \\
Power output & $\mathrm{kJ} / \mathrm{kg}$ & 125.16 \\
LHV of fuel & & 29.89 \\
\end{tabular}

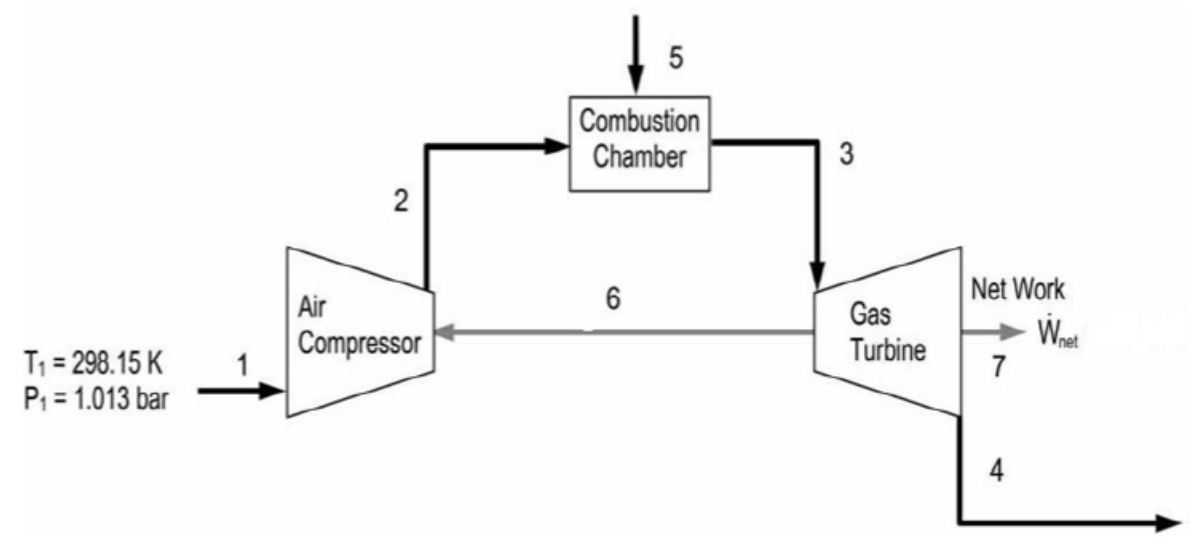

Fig. 1. A schematic diagram for a simple GT cycle 


\section{Power Plant Components Energetic and Exergetic} Analyses

The energetic and exergetic efficiencies of the entire unit that makes up the selected gas turbine plant were evaluated using MATLAB R2010a and Microsoft Excel 2010. For the purpose of investigating the effect of interaction of the plant's units on the energetic and exergetic efficiencies, the thermal power plant unit was grouped into subsystem and overall system, as clearly presented in Fig. 1. The energy and exergy balances on inlet and exit streams of each process unit were used in the estimation of their energetic and exergetic efficiencies.

\section{Modelling of Gas Turbine Engine}

The major components of simple Gas Turbine (GT) are compressor, combustion chamber and turbine. The compressor takes in air from the atmosphere, compresses it to a higher temperature and pressure which is then sent to the combustor and the products of combustion are expanded in the turbine. Equation 1 to 40 depict the governing thermodynamics relations used for modelling the simple gas turbine engine. In this study, energy and exergy models are employed for assessing the gas turbine performance.

\section{Energy Analysis}

In this study, the energy analysis was carried out using the first law of thermodynamics for a thermal system. It is possible to calculate the cycle thermal efficiency, which is the ratio of the work output to the heat input. Also, the energy loss in each component and the entire plant can be computed using energy balance.

For any control volume at steady state with negligible potential and kinetic energy changes, energy balance reduces to (Avval et al., 2011):

$\dot{Q}-\dot{W}=\sum \dot{m}_{e} h_{e}-\sum \dot{m}_{i} h_{i}$

The energy balance equations for various components of the gas turbine plant shown in Fig. 1 are as follows:

\section{Air Compressor}

The compression ratio $\left(r_{p}\right)$ can be defined as:

$$
r_{p}=\frac{P_{2}}{P_{1}}
$$

where, $p_{1}$ and $p_{2}$ are the compressor inlet and outlet air pressures, respectively.

The isentropic efficiency for the compressor is expressed as:

$$
\eta_{C} \frac{\left[\left(r_{p}\right)^{\frac{\gamma a-1}{\gamma a}}-1\right]}{\left(\frac{T_{2}}{T_{1}}-1\right)}
$$

where, $T_{1}$ and $T_{2}$ are the compressor inlet and outlet air temperatures, respectively.

Compressed air temperature can be written in terms of the pressure ratio and the inlet compressor temperature as:

$T_{2}=T_{1}\left[1+\frac{\left(r_{p}\right)^{\frac{\gamma_{a}-1}{\gamma_{a}}}-1}{\eta_{c}}\right]$

where, $T_{2}$, is the temperature in $K$ of the compressed air entering combustion chamber and $\eta_{c}$, is the compressor's isentropic efficiency.

At full load, the compressor work rate, $W_{c}$ can be written in terms of the pressure ratio and the inlet compressor temperature as:

$\dot{W}_{c}=\frac{\dot{m}_{a} c_{p a} T_{1}}{\eta_{c}}\left(\left(r_{p}\right)^{\frac{\gamma_{a}-1}{\gamma_{a}}}-1\right)$

where, $c_{p a}$ is the specific heat capacity of air which is considered in this study as a function of temperature and can be fitted using Equation 6 for temperature in the range of $200 \mathrm{~K}<\mathrm{T}<800 \mathrm{~K}$ (Rahman et al., 2011a; Kurt et al., 2009):

$$
\begin{aligned}
& c_{p a}(T)=1.04841-\left(\frac{3.8371 T}{10^{4}}\right)+\left(\frac{9.45371 T^{2}}{10^{7}}\right) \\
& -\left(\frac{5.49031 T^{3}}{10^{10}}\right)+\left(\frac{7.9298 T^{4}}{10^{14}}\right)
\end{aligned}
$$

The energy input to the air compressor at ambient temperature is calculated using:

$\dot{Q}_{c 1}=\dot{m}_{a}\left(c_{p a} T_{2}-c_{p a} T_{a}\right)$

where, $T_{a}$ is the ambient temperature.

Energy input to the air compressor at specific inlet temperature $\left(T_{1}\right)$ is given as:

$\dot{Q}_{c 2}=\dot{m}_{a}\left(c_{p a} T_{2}-c_{p a} \bar{T}_{1}\right)$

The energy loss in the compressor due to the inlet air temperature difference is given as:

$\dot{Q}_{\text {closs }}=\dot{m}_{a}\left(c_{p a} T_{2}-c_{p a} T_{a}\right)-\dot{m}_{a}\left(c_{p a} T_{2}-c_{p a} \bar{T}_{1}\right)$ 
where:

$$
\bar{T}_{1}=\frac{T_{a}+T_{2}}{2}
$$

\section{Combustion Chamber}

The energy balance in the combustion chamber is given by (Ibrahim et al., 2010):

$$
\dot{m}_{a} C_{p a} T_{2}+\dot{m}_{f}\left(L H V+C_{p f} T_{f}\right)=\left(\dot{m}_{a}+\dot{m}_{f}\right) C_{p g} T_{3}
$$

Energy loss in the combustion chamber is determined using Equation 11:

$$
\dot{Q}_{C C \text { loss }}=\dot{m}_{a} C_{p a} T_{2}+\dot{m}_{f} L H V=\dot{m}_{f} C_{p g} T_{3}
$$

where, $\dot{m}_{f}$, is fuel mass flow rate $(\mathrm{kg} / \mathrm{s}), \dot{m}_{a}$ is air mass flow rate $(\mathrm{kg} / \mathrm{s}), L H V$ is low heating value, $T_{3}$ is turbine inlet temperature $(K), C_{p f}$ is specific heat of fuel and $T_{f}$ is temperature of fuel $(K) . C_{p g}$ is the specific heat capacity of combustion product (gas) which is considered in this work to be a temperature variable function and can be fitted by Equation 12 for temperature in the range of 1000 $\mathrm{K}<\mathrm{T}<1500 \mathrm{~K}$ (Tahouni et al., 2012; Kurt et al., 2009):

$$
\begin{aligned}
& c_{p g}(T)=0.991615+\left(\frac{6.99703 T}{10^{5}}\right) \\
& +\left(\frac{2.7129 T^{2}}{10^{7}}\right)-\left(\frac{1.22442 T^{3}}{10^{10}}\right)
\end{aligned}
$$

From Equation 9, the fuel-air ratio $(f)$ is expressed as:

$f=\frac{\dot{m}_{f}}{\dot{m}_{a}}=\frac{C_{p g} T_{3}-C_{p a} T_{1}\left(1+r_{p g}\right)}{L H V+C_{p f} T_{f}-C_{p g} T_{3}}$

where:

$r_{p g}=\frac{(r p)^{\frac{\left(\gamma_{a}-1\right)}{\gamma_{a}}}-1}{\eta_{c}}$

The pressure drop across the combustion chamber $\left(\Delta P_{c c}\right)$ is usually around $2 \%$ (Adrian and Dorin, 2010; Avval et al., 2011). The turbine inlet pressure $\left(P_{3}\right)$ can be calculated as:

$$
P_{3}=P_{2}\left(1-\Delta P_{c c}\right)
$$

Where:

$P_{3} \quad=$ Turbine entry level pressure in $\mathrm{Pa}$

$P_{2}=$ The combustion chamber inlet temperature
$\Delta P_{c c}=$ Pressure drop across the combustion chamber

\section{Gas Turbine}

The isentropic efficiency for turbine can be written in terms of the turbine pressure ratio, the turbine inlet temperature and turbine exit temperature as:

$\eta_{T}=\frac{1-\left(\frac{T_{4}}{T_{3}}\right)}{1-\left(r_{T}\right)^{\frac{1-\gamma_{g}}{\gamma_{g}}}}$

where, $r_{T}$ is the turbine pressure ratio, $r_{T}=P_{3} / P_{4}$

The exhaust gases temperature from the gas turbine is given as:

$T_{4}+T_{3}\left\{1-\eta_{T}\left[1-\left(\frac{P_{3}}{P_{4}}\right)^{\frac{1-\gamma_{g}}{\gamma_{g}}}\right]\right\}$

The shaft work rate of the turbine is written in terms of the pressure ratio and the turbine inlet temperature as:

$$
\dot{W}_{T}=\dot{m}_{g} c_{p g} T_{3} \eta_{T}\left[1-\left(r_{T}\right)^{\frac{1-\gamma_{g}}{\gamma_{g}}}\right]
$$

The network rate of the gas turbine is given in terms of the pressure ratio, compressor inlet temperature and turbine inlet temperature as:

$$
\begin{aligned}
& \dot{W}_{n}=\dot{m}_{g} c_{p g} T_{3} \eta_{T}\left[1-\left(r_{T}\right)^{\frac{1-\gamma_{g}}{\gamma_{g}}}\right] \\
& -\frac{\dot{m}_{a} c_{p a} T_{1}}{\eta_{c}}\left[\left(r_{p}\right)^{\frac{\gamma_{a}-1}{\gamma_{a}}}-1\right]
\end{aligned}
$$

where:

$$
\dot{m}_{g}=\dot{m}_{a}+\dot{m}_{f}
$$

$c_{p g}$ is the specific heat capacity of combustion product (gas) and it is given as in Equation 12.

The power output is expressed in terms of the pressure ratio, compressor inlet temperature and turbine inlet temperature as:

$$
P=m_{g}\left[c_{p g} T_{3} \eta_{T}\left(1-\left(r_{p}\right)^{\frac{1-\gamma_{g}}{\gamma_{g}}}\right)-\frac{c_{p a} T_{1}}{\eta_{c}}\left(\left(r_{p}\right)^{\frac{\gamma_{a}-1}{\gamma_{a}}}-1\right)\right]
$$

Energy input in the turbine is given as: 


$$
\dot{Q}_{T}=\dot{m}_{g} c_{p g} T_{3}
$$

Energy utilized for turbine work is calculated as follows:

$$
\dot{Q}_{T w}=\dot{m}_{g}\left(c_{p g} T_{3}-c_{p g T E T} T E T\right)
$$

where, $T_{3}$ is the combustion chamber exit temperature and TET is turbine exhaust temperature.

Energy loss from the turbine is given as:

$$
\dot{Q}_{\text {Tloss }}=\dot{m}_{g}\left(c_{p g T E T} T E T\right)
$$

The total energy loss in the turbine system is calculated by:

$$
\dot{Q}_{\text {TTloss }}=\dot{Q}_{\text {Closss }}+\dot{Q}_{\text {CCloss }}+\dot{Q}_{\text {Tloss }}
$$

The gas turbine thermal efficiency $\left(\eta_{\mathrm{th}}\right)$ can be determined by Equation 26:

$$
\eta_{t h}=\frac{\dot{w}_{n}}{\dot{m}_{f} L H V}
$$

Equation 25 is also known as the first law efficiency of gas turbine (Mozafari et al., 2010).

The Specific Fuel Consumption (SFC) is determined by:

$$
S F C=\frac{3600}{w_{n}} f
$$

where, $f$ (fuel-air mass ratio) is given is given by Equation 12.

The Heat Rate (HR) (the consumed thermal energy to generate unit energy of electrical energy) can be expressed as:

$$
H R=\frac{3600}{\eta_{t h}}
$$

\section{Exergy Analysis}

The second law of thermodynamics complements and enhances the analysis of energy system using appropriate calculation of the real thermodynamic inefficiencies and losses from the system being considered. The exergy method is based on the second law of thermodynamics in which complete transformation of heat into work is not possible (Alcides, 1999).

A general exergy-balance equation applicable to any thermal system component may be formulated using the first and second laws of thermodynamics (Oh et al.,
1996; Ebadi and Gorji-Bandpy, 2005). The thermomechanical exergy stream may be decomposed into its thermal and mechanical components so that the balance in rate form gives:

$\dot{E}_{i}^{P H}-\dot{E}_{e}^{P H}=\left(\dot{E}_{i}^{T}-\dot{E}_{e}^{T}\right)+\left(\dot{E}_{i}^{P}-\dot{E}_{e}^{P}\right)$

where, the subscripts $i$ and $e$ represent inlet and exit states; $\dot{E}^{P H}$ is the physical exergy of a material stream, $\dot{E}^{T}$ is the thermal component of the exergy stream, $\dot{E}^{P}$ is the mechanical component of the exergy stream, the terms on the left-hand side of the equation represent the change in exergy of the flow stream, the first and second terms on the right-hand side of the equation represent the changes in the thermal and mechanical components of the exergy stream respectively.

The thermal and mechanical components of the exergy stream for an ideal gas with constant specific heat may be written respectively as (Ebadi and Gorji-Bandpy, 2005; Abam et al., 2011):

$$
\dot{E}^{T}=\dot{m} c_{p}\left[\left(T=T_{0}\right)-T_{0} \ln \frac{T}{T_{0}}\right]
$$

and:

$$
\dot{E}^{P}=\dot{m} R T_{0} \ln \frac{P}{P_{0}}
$$

Where:

$P_{0}$ and $T_{0}=$ The pressure and temperature, respectively, at standard state; $\dot{m}$ is the mass flow rate of the working fluid

$R \quad=$ The gas constant

$c_{p} \quad=$ The specific heat at constant pressure

In steady state, exergy balance for control volume is given as (Bejan et al., 1996; Kotas, 1995):

$\dot{E}_{x}=\sum_{j}\left(1-\frac{T_{0}}{T_{j}}\right) \dot{Q}_{j}+\dot{W}_{C V}+\sum_{i} m_{i} e_{i}-\sum_{e} m_{e} e_{e}$

The subscripts $i, e, j$ and 0 refer to conditions at inlet and exits of control volume boundaries and reference state. Equation 32 can be written as:

$E_{i}^{\text {tot }}-E_{e}^{\text {tot }}-E_{D}=0$

The implication of Equation 33 is that the exergy change of a system during a process is equal to the difference between the net exergy transfer through the system boundary and the exergy destroyed within the system boundaries as a result of irreversibilities. 
The exergy-balance equations and the exergy destroyed during the process taking place in each component of the power plant are expressed as follow:

Air Compressor:

$$
\begin{aligned}
& \dot{E}^{W A C}=\left(\dot{E}_{1}^{T}-\dot{E}_{2}^{T}\right)+\left(\dot{E}_{1}^{P}-\dot{E}_{2}^{P}\right)+T_{0}\left(\dot{S}_{1}-\dot{S}_{2}\right) \\
& \dot{E}_{D A C}=T_{0}\left(\dot{S}_{2}-\dot{S}_{1}\right) \\
& =\dot{m} T_{0}\left[c_{p 1-2} \ln \left(T_{2} / T_{1}\right)-R \ln \left(P_{2} / P_{1}\right)\right]
\end{aligned}
$$

Combustion Chamber:

$$
\begin{aligned}
& \dot{E}^{C H E}+\left(\dot{E}_{2}^{T}+\dot{E}_{5}^{T}-\dot{E}_{3}^{T}\right)+\left(\dot{E}_{2}^{P}+\dot{E}_{5}^{P}-\dot{E}_{3}^{P}\right) \\
& +T_{0}\left(\dot{S}_{3}-\dot{S}_{2}+\dot{S}_{5}+\frac{\dot{Q}_{C C}}{T_{0}}\right)=0 \\
& \dot{E}_{D C}=T_{0}\left[\dot{S}_{3}-\dot{S}_{2}+\dot{S}_{5}+\frac{\dot{Q}_{C C}}{T_{0}}\right] \\
& =\dot{m} T_{0}\left\{\begin{array}{l}
\left(c_{p 2-3} \ln \left(T_{3} / T_{2}\right)-R \ln \left(P_{3} / P_{2}\right)\right) \\
+\left(c_{p 5} \ln \left(T_{5} / T_{0}\right)-R \ln \left(P_{5} / P_{0}\right)\right) \\
c_{p 2-3}\left(T_{3}-T_{2}\right) \\
T_{i n C C}
\end{array}\right\}
\end{aligned}
$$

Gas Turbine:

$$
\begin{aligned}
& \dot{E}^{W G T}=\left(\dot{E}_{3}^{T}-\dot{E}_{4}^{T}\right)+\left(\dot{E}_{3}^{P}-\dot{E}_{4}^{P}\right)+T_{0}\left(\dot{S}_{3}-\dot{S}_{4}\right) \\
& \dot{E}_{D G T}=\dot{m} T_{0}\left[c_{p 3-4} \ln \left(T_{4} / T_{3}\right)-R \ln \left(P_{4} / P_{3}\right)\right]
\end{aligned}
$$

For a control volume at steady state, the exergetic efficiency is given as:

$$
\varepsilon=\frac{\dot{E}_{P}}{\dot{E}_{F}}=1-\frac{\dot{E}_{D}+\dot{E}_{L}}{\dot{E}_{F}}
$$

where, the rates at which the fuel is supplied and the product is generated are denoted by $\dot{E}_{F}$ and $\dot{E}_{P}$, respectively. $\dot{E}_{D}$ and $\dot{E}_{L}$ denote the rates of exergy destruction and exergy loss, respectively.

The $i^{\text {th }}$ component efficiency defect denoted by $\delta_{i}$ is given by Equation 38 (Abam et al., 2011):

$$
\delta_{i}=\frac{\sum \Delta \dot{E}_{D i}}{\sum \Delta \dot{E}_{x i n}}
$$

where, $\Sigma \Delta \dot{E}_{D i}$ is the sum of change in total rate of exergy destruction and $\Sigma \Delta \dot{E}_{x i n}$ is the sum of change in total rate of exergy flow into the plant.

The overall exergetic efficiency of the entire plant is expressed as:

$\psi_{i}=\frac{\dot{W}_{\text {net }}}{\dot{E}_{x \text { fuel }}}$

The amount of exergy loss rate per unit power output as important performance criteria is given as:

$\xi=\frac{\dot{E}_{D T o t a l}}{\dot{W}_{\text {net }}}$

where, $\xi$ is the exergetic performance coefficient.

\section{Results and Discussion}

\section{Effects of Operating Conditions on Performance of Gas Turbine Plants}

The simulation results of the effect of operation conditions on gas turbine power plant performance are presented in this sub-section. The effects of operation conditions on the power output, heat rate, specific fuel consumption and efficiency are obtained using computational model developed with energy balance and employing MATLAB codes (MATLAB R2010a). In this study, the effect of operating atmospheric conditions on gas turbine is considered purposely to show sensitivity of gas turbine performance to the environmental condition. The results obtained are presented in Fig. 2 to 13 based on theoretical relationships earlier mentioned.

\section{Effect of Compression Ratio}

Figure 2 shows the relation between cycle thermal efficiency and compression ratios for Turbine Inlet Temperatures (TITs) between 900 and $1500 \mathrm{~K}$. It can be seen that the thermal efficiency linearly increases at lower compression ratio as well as at higher TIT until certain value of compression ratio is reached. The thermal efficiency decreases with increase compression ratio, this limit is dependent on the TIT. The maximum TIT is limited by metallurgical considerations. The blades of the turbine are under great mechanical stress and the temperature of the blade material must be kept to a safe working value (Eastop and McConkey, 2009; Rajput, 2007). The temperature of the gases entering the turbine can be raised, provided a means of blade cooling is available. In aircraft practice, where the life expectancy of the engine is shorter, the maximum temperatures used are usually higher than those used in industrial and marine gas turbine units; more expensive alloys and blade cooling allow maximum temperatures of above $1600 \mathrm{~K}$ to be attained. 


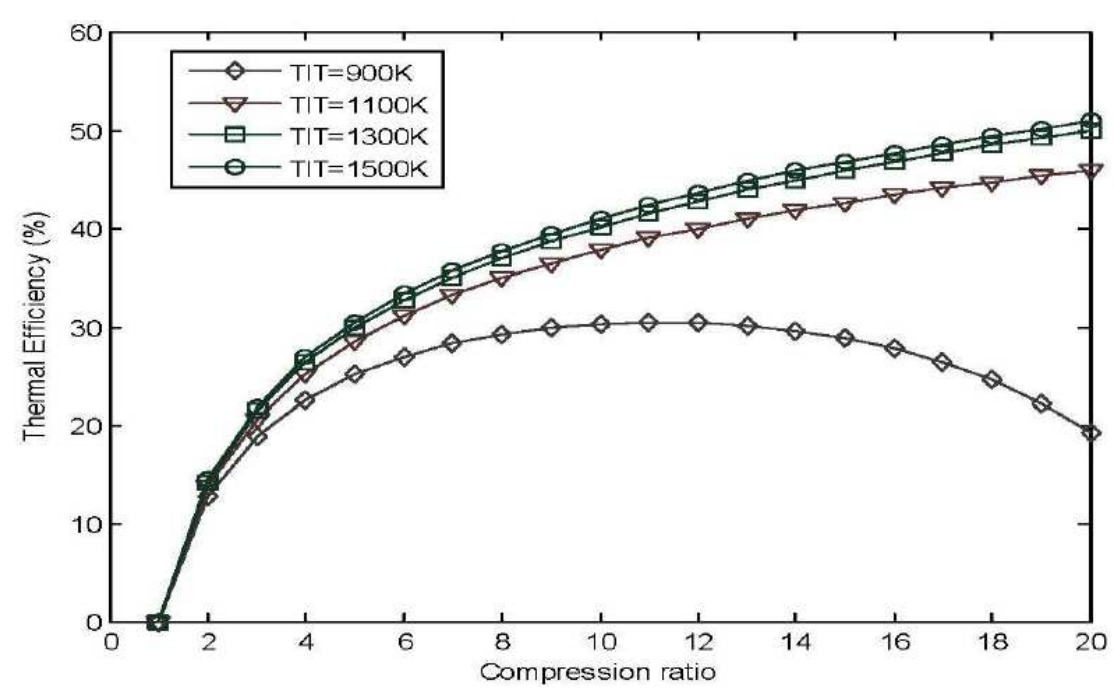

Fig. 2. Effect of Compression ratio and TIT on thermal efficiency

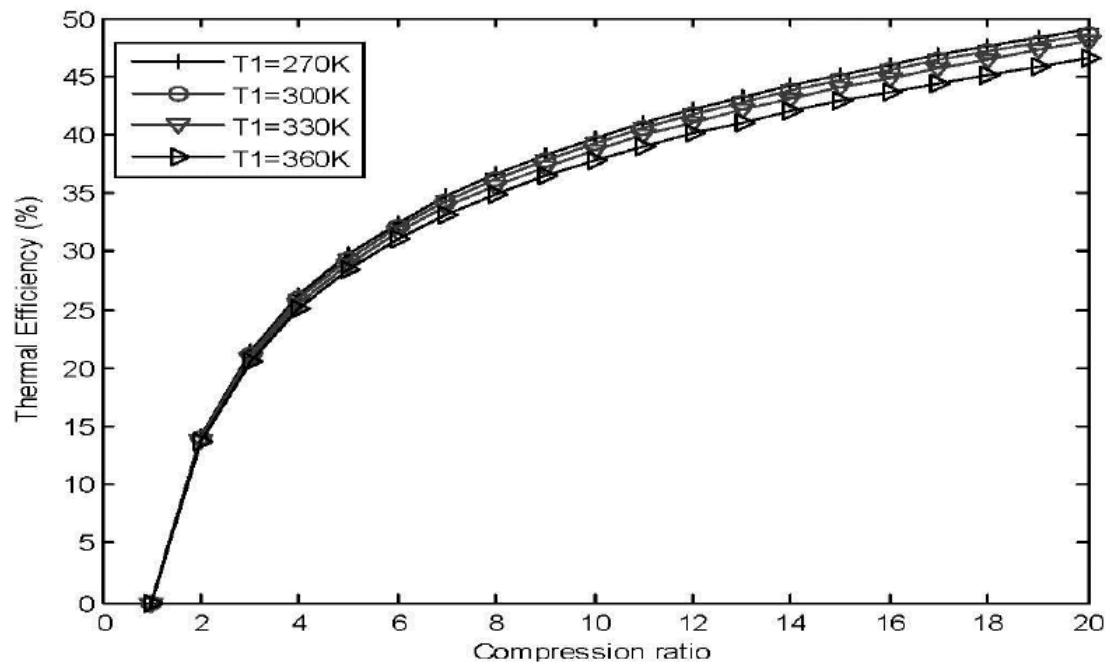

Fig. 3. Effect of Compression Ratio and ambient temperature (T1) on Thermal Efficiency

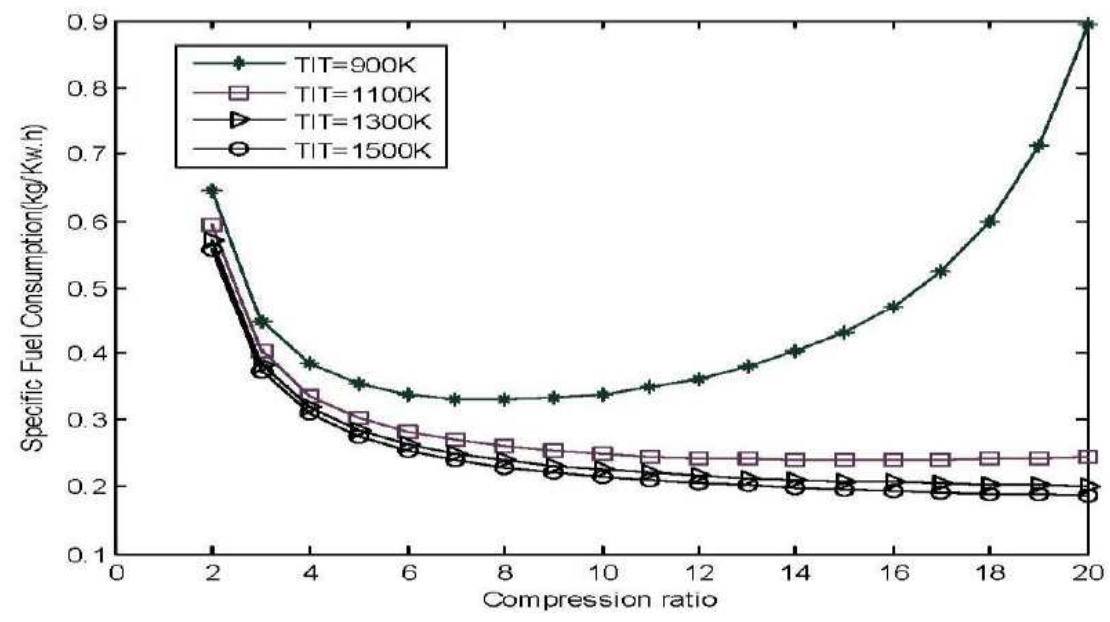

Fig. 4. Effect of Compression ratio and TIT on Specific Fuel Consumption 


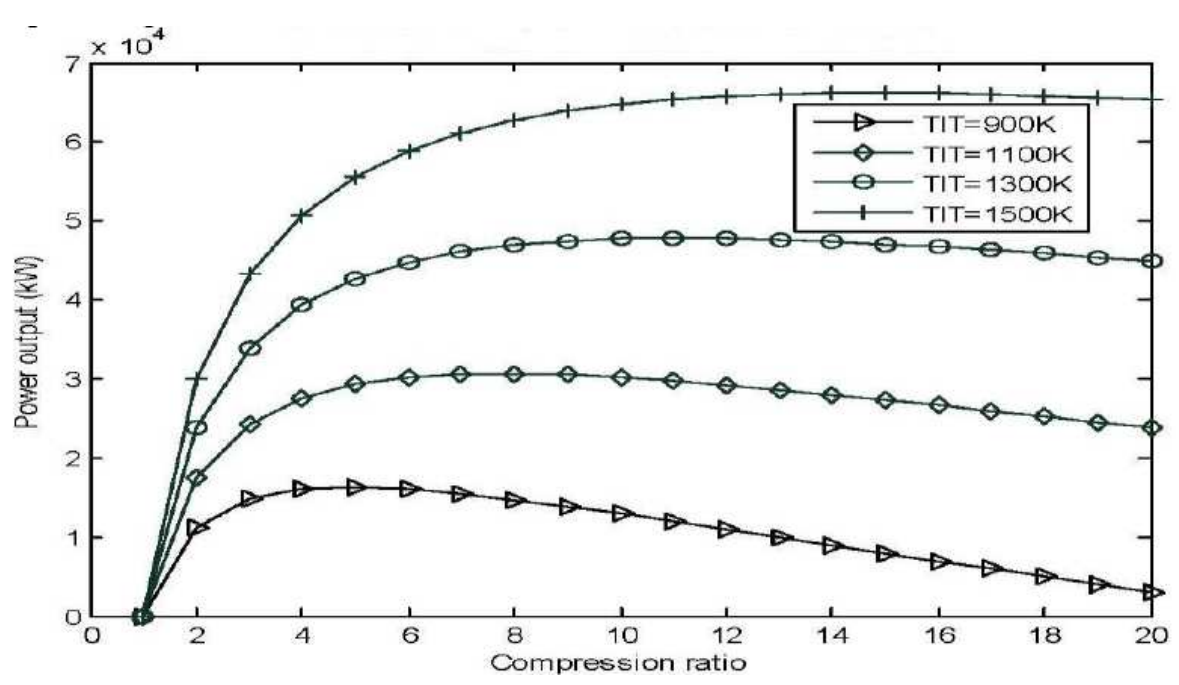

Fig. 5. Effect of compression ratio and TIT on power output

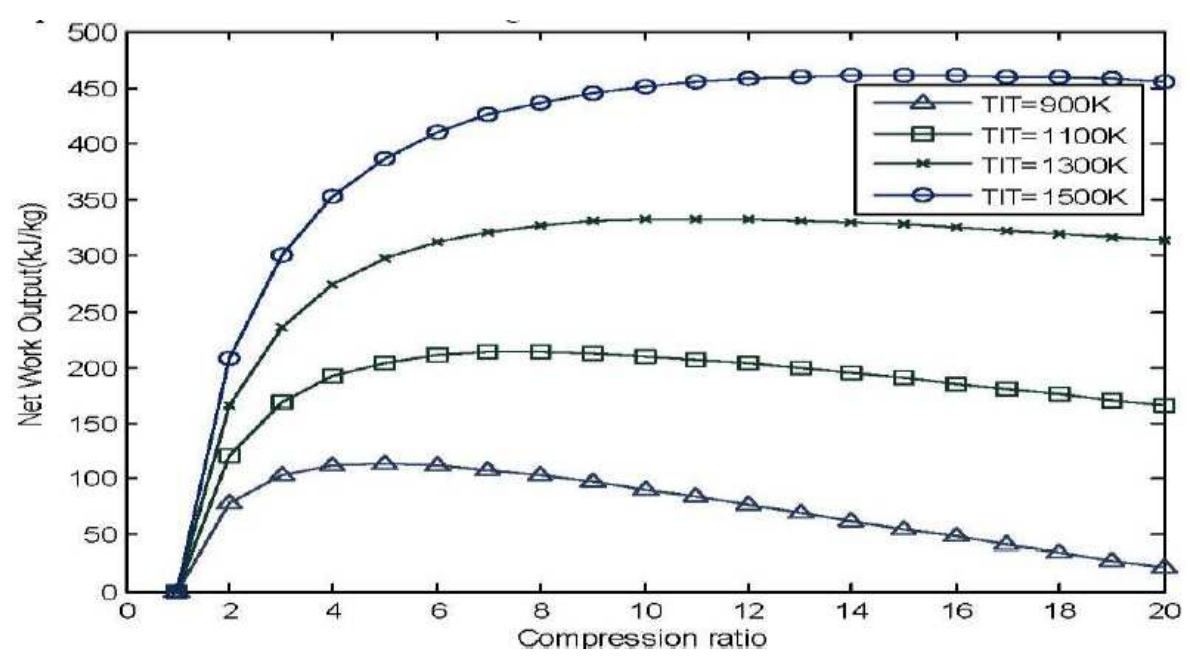

Fig. 6. Effect of compression ratio and TIT on network output

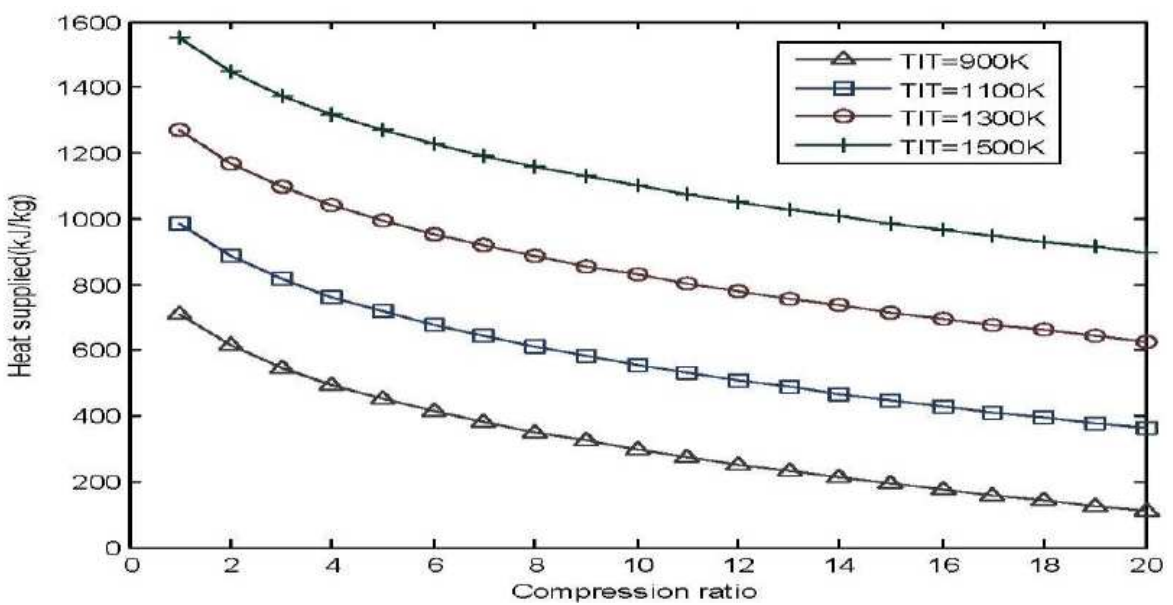

Fig. 7. Effect of compression ratio and TIT on heat supplied 


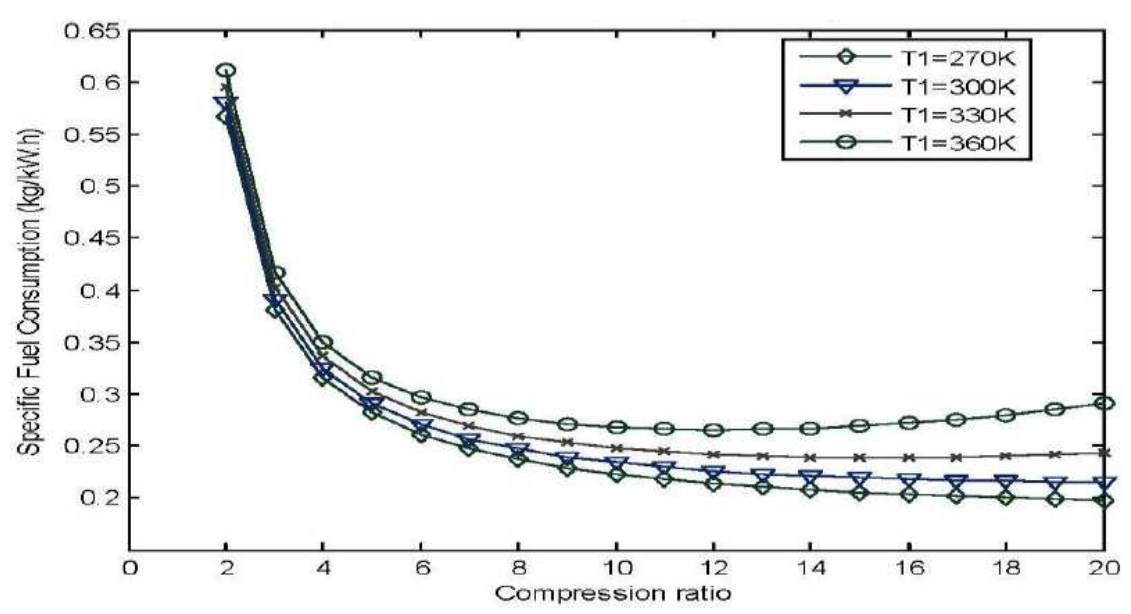

Fig. 8. Effect of ambient temperature and compression ratio on specific fuel consumption

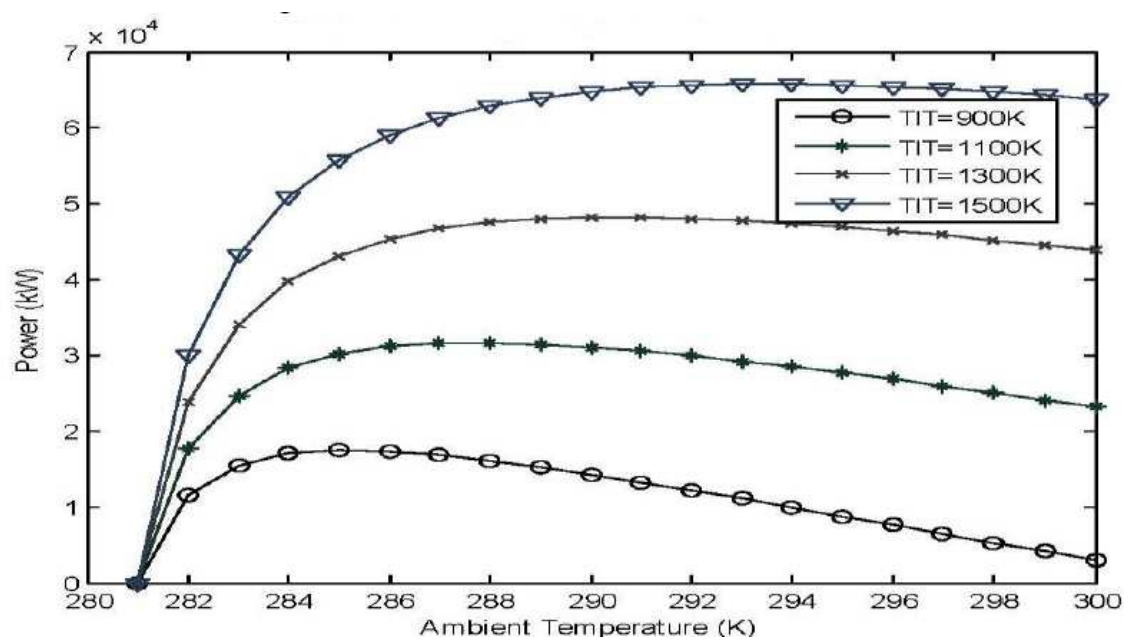

Fig. 9. Effect of ambient temperature and TIT on Power Output

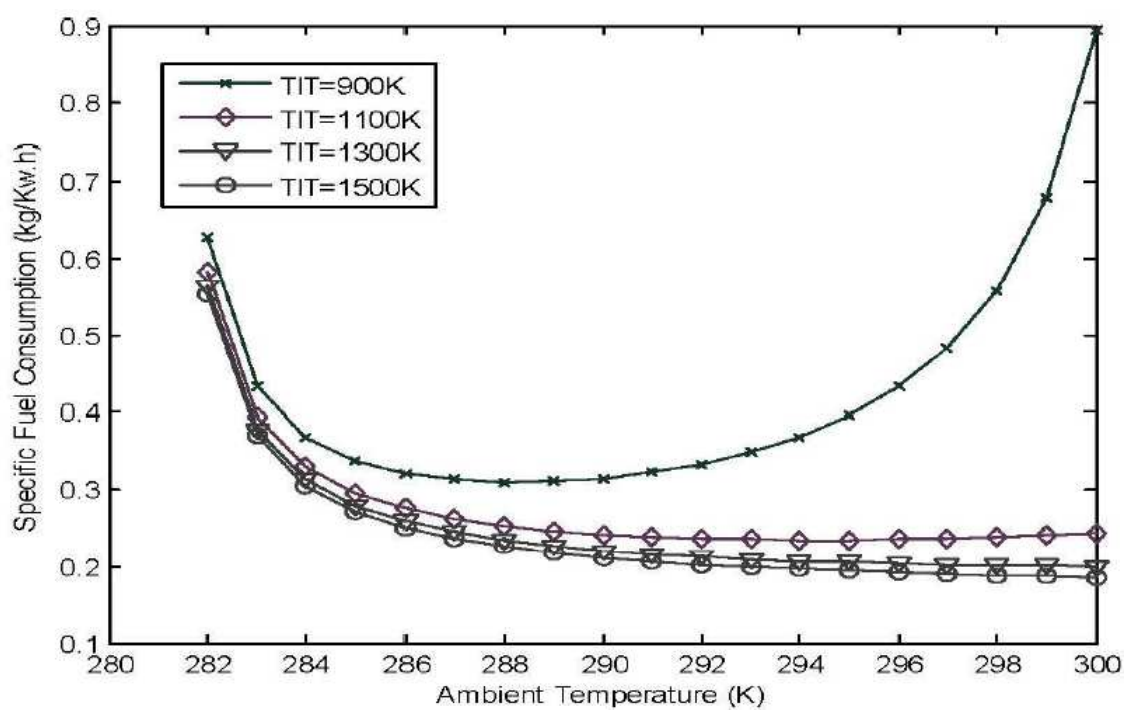

Fig. 10. Effect of ambient temperature and turbine inlet temperature on specific fuel consumption 


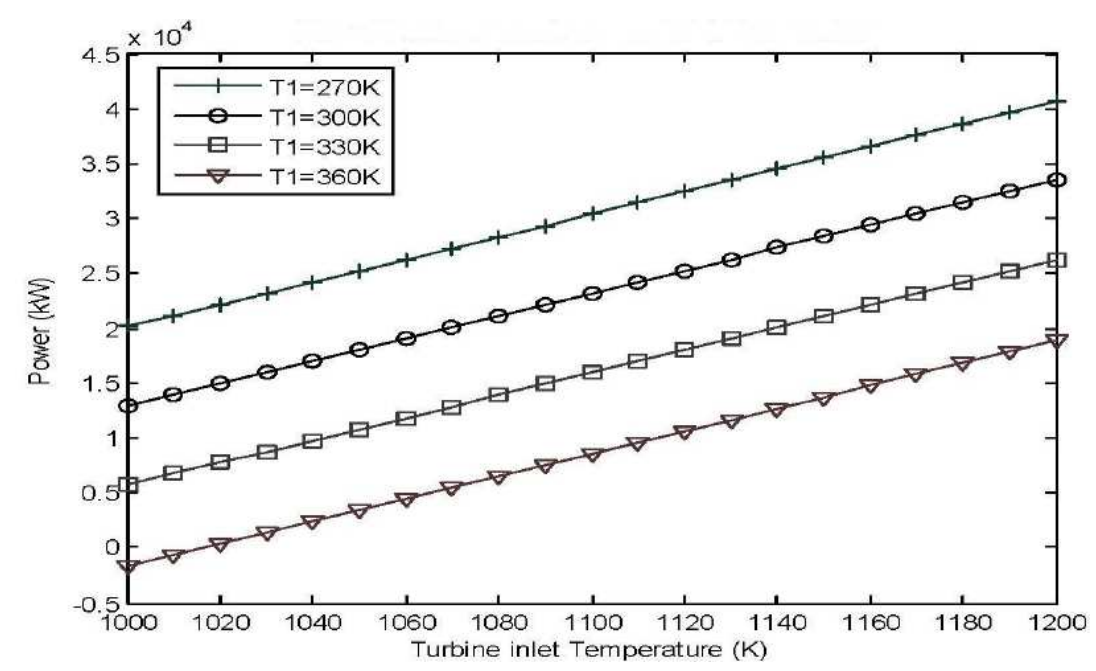

Fig. 11. Effect of turbine inlet temperature and ambient temperature on power output

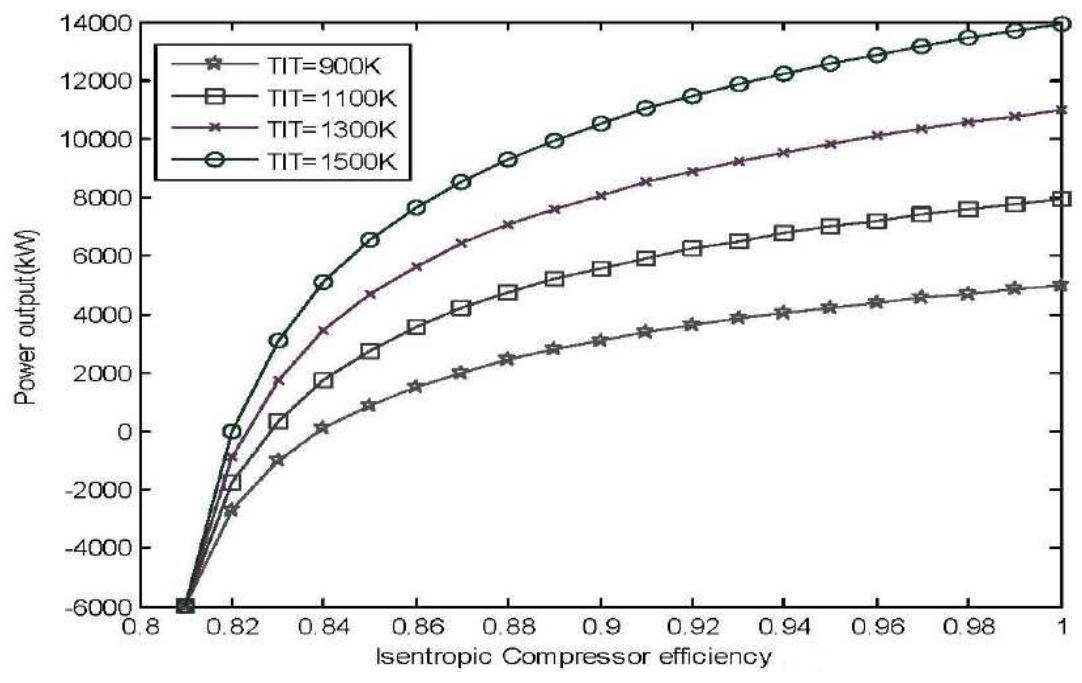

Fig. 12. Effect of turbine inlet temperature and isentropic compressor efficiency on power output

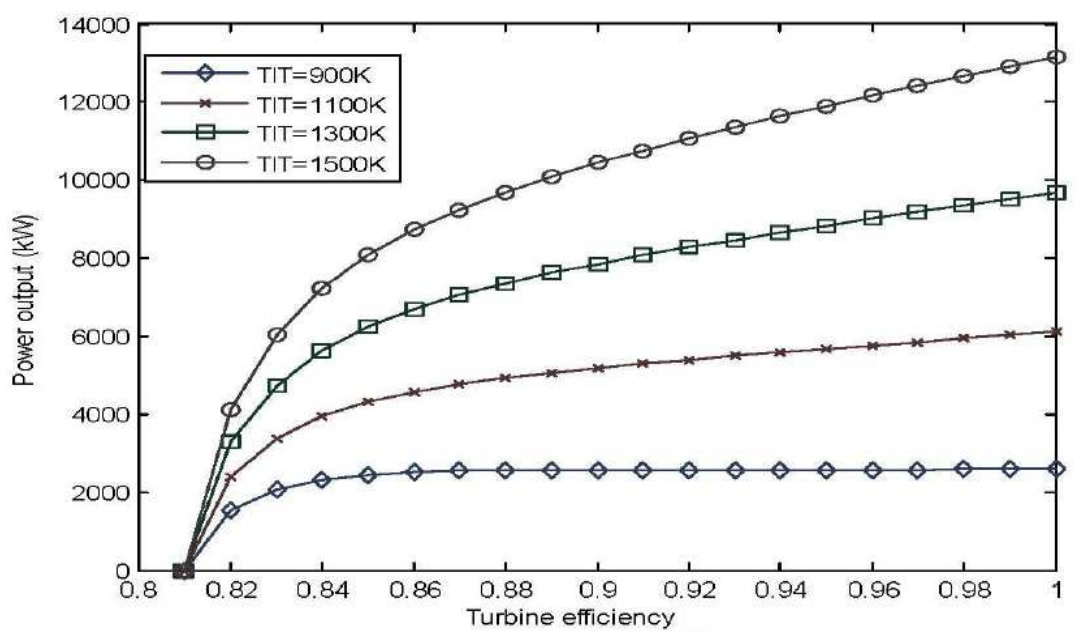

Fig. 13. Effect of Turbine inlet temperature and Isentropic Turbine Efficiency on Power Output 
At lower TIT (e.g., at $900 \mathrm{~K}$ ), there is decrement in thermal efficiency drastically with increase in compression ratio. But as the turbine inlet temperature increases, the peaks of the curves flatten out giving an increased range of optimum efficiency. Result of the present study is in agreement to that of Rahman et al (2011a).

Figure 3 presents the effect of compression ratio and ambient temperature (T1) on the thermal efficiency of gas turbine engine. It is observed that thermal efficiency increases with increase in compression ratio but slightly decreases with small increase in ambient temperature (T1). From thermodynamic point of view, as the compressor pressure ratio increases, the temperature rise across the compressor also increases. This in turn reduces the combustor temperature rise necessary to achieve a given turbine inlet temperature. As a result, the combustor heat input decreases and cycle efficiency increases. A comparison between the results from the present study and that of previous works (Ibrahim et al., 2010; Rahman et al., 2010) reveals an acceptable agreement.

Figure 4 shows the effect of compression ratio $r_{p}$ and turbine inlet temperature TIT on Specific Fuel Consumption (SFC). It is observed that the SFC decreases linearly with increase of compression ratio up to about $r_{p}=3$ and outside this value, SFC also decreases with increase in TIT. As stated earlier, increase in compression ratio for the same TIT will raise the temperature of the air entering the combustion chamber and decreases the heat added in the combustion chamber. This invariable leads to decrease in SFC. At lower TIT $(900 \mathrm{~K})$, there is increment in SFC drastically with increase in compression ratio about $r_{p}=3$ and above. But as the turbine inlet temperature increases, the peaks of the curves flatten out giving a decreased range of least SFC. A comparison between the results from the present study and that of previous works (Ibrahim et al., 2010; Rahman et al., 2010) reveals an acceptable agreement. As TIT increases from 900 to $1500 \mathrm{~K}$, SFC decreases from 0.9 to $0.2 \mathrm{~kg} / \mathrm{kWh}$.

The power output of a gas turbine is a function of TIT and compression ratio (Equation 21). The temperature of air leaving the compressor and entering in combustion chamber depends upon the compressor pressure ratio. By increase the compression ratio, the outlet temperature increases. So, the temperature difference between compressed air and combustion chamber decreases. As the compression ratio increases, the air exiting the compressors is hotter, therefore less fuel is required (lowering the air fuel ratio) to reach the desired turbine inlet temperature, for a fixed gas flow to the gas turbine. The work required in the compressor and the power output of the gas turbine, steadily increases with compression ratio. Figure 5 presents the variation in the maximum power output with compression ratio at different TITs. It is observed that at lower compression ratios the power output increases linearly with TIT. The peaks (maximum power output) of the curves vary with TIT such that at higher TITs, the peaks flatten out. A comparison between the results from the present study and that of previous works (Rahman et al., 2011b) reveals an acceptable agreement.

From Equation 19, the network output of a gas turbine is a function of TIT and compression ratio. As the compression ratio increases, the work required in the compressor of the gas turbine, steadily increases with compression ratio. At high pressure ratio, the compressor and turbine works increase but their difference causes the net gas-turbine work output to drop. Therefore, it is desirable to select lower value of compressor pressure ratio for higher plant network output. Figure 6 shows the variation of net-work output with compression ratio and TIT. With increase in compression ratio, the net-work output decreases. At high turbine inlet temperature, the peaks of net-work output flatten out. As TIT increases from 900 to 1500 $\mathrm{K}$, the network output increases from 25 to $450 \mathrm{~kJ} / \mathrm{kg}$.

The variation of heat supplied with compression ratio and TIT is presented in Figure 7. It is observed that heat supplied increases with TIT but decreases with compression ratio. Since compression ratio increases the temperature of the air entering the combustion chamber, this implies that less heat is needed for combustion to take place in the combustion chamber. Therefore, increase in compression ratio for the same turbine inlet temperature decreases the heat supplied.

Figure 8 shows the effect of compression ratio and ambient temperature on specific fuel consumption. It is observed that the specific fuel consumption increases with increased ambient temperature. At higher $\mathrm{T} 1$, the air density decreases, resulting in a decrease in air mass low rate. Thus, the fuel mass flow rate increases since the air to fuel ratio is kept constant. Therefore, the specific fuel consumption increases with increase in ambient temperature due to the flue gas losses.

The increase in compression ratio for gas turbine power plant leads to a continuous decrease of specific fuel consumption.

\section{Effect of Ambient Temperature}

Figure 9 shows the effect of ambient temperature and TIT on the power output. It is observed that at lower ambient temperature the power output increases linearly with TIT. The power output increases with increase in TIT but decreases with increase in ambient temperature. As the ambient temperature increases, the specific work of the compressor increases (Nag, 2008), thus, reducing the net-work output and invariably reducing the power output of the gas turbine. Also, increasing the TIT leads 
to an increase in the turbine work output, hence an increase in the net power output.

Figure 10 shows variation of SFC with ambient temperature and TIT. At lower ambient temperatures, the SFC decreases linearly with ambient temperature. The SFC increases with increasing ambient temperature and also with lower TIT. The effect of variation of SFC is more significant at higher ambient temperature and lower TIT. As TIT increases from 900 to $1500 \mathrm{~K}$ and ambient temperature increases from 280 to $300 \mathrm{~K}$, the SFC decreases 0.9 to $0.2 \mathrm{~kg} / \mathrm{kWh}$.

\section{Effect of Turbine Inlet Temperature}

The variation of power output with ambient temperature and TIT is shown in Fig. 11. It can be seen that the power output increases linearly with TIT while it decreases with increase in the ambient temperature $\mathrm{T} 1$. The increase in power output due to TIT is as a result of the net-work output increase. Figure 11 also shows that the gas turbine power output is affected by ambient temperature due to the change in air density and compressor work. Since a lower ambient temperature leads to a higher air density and a lower compressor work, that in turn gives a higher gas turbine output power. However, when the ambient temperature increases, the specific work of the compressor increases thus, reducing power output for gas turbine.

\section{Effect of Compressor and Turbine Efficiencies}

Figure 12 and 13 present the effect of the compressor and turbine isentropic efficiencies on the power output for TITs. The power output increases with increase in the compressor and turbine isentropic efficiencies. This implies that the thermal losses have been reduced in compressor and turbine. This leads to increased power output. The rate of increase in power output is more significant at higher TIT and higher isentropic compressor and turbine efficiencies.

\section{Performance Evaluation of the Gas Turbine Power Plant Using Energy and Exergy Analyses}

Energy and exergy analyses are important to explain how energy flows interact with each other and how the energy content of resources is exploited. The energetic efficiency and exergetic efficiency have wide range of application at system and component level (Mirandola et al., 2000; Oyedepo, 2014). A complete analysis of the thermodynamic performance of a process generally requires the use of both energy and exergy analyses.

\section{Energy Analysis}

The average of the operating data of the gas turbine power plant for the period of six years $(2005$ to 2010) is presented in Table 2. The energy loss experienced in the gas turbine components are shown in Table 3. The data provided in Table 1 were employed as inputs for analysis with the use of Equation 9, 11, 24, 25 and 26. For the period of six years, the thermal efficiency is $36.68 \%$ (Table 3 ). Energy performance analysis also shows that the turbine has the highest proportion of energy loss $(31.98 \%)$ in the plant.

As earlier mentioned, the operating parameters have effect on gas turbine engine performance. Figure 14 presents the effect of variation in air compressor inlet temperature on heat energy loss in the air compressor. The energy losses in air compressor increase at high ambient temperature. The air compressor work increases as inlet air temperature increases which leads to a decrease in net work of the gas turbine. Air compressor work can be minimized when the air inlet temperature and mass flow rate are reduced. This shows that compressor work can be managed by the compressor inlet air temperature.

Compression ratio is another parameter that affects performance of gas turbine power plant. Figure 15 shows the effect of compression ratio on energy loss in air compressor. Increase in pressure ratio brings about decrease in energy loss in air compressor. This shows that the compressor work can be reduced by decreasing the compression ratio.

Figure 16 shows the effect of air mass flow rate on heat energy loss in the combustion chamber. Heat energy losses in the combustion chamber decrease with increase in air mass flow rate. This implies that high mass flow rate of air can minimize the energy losses in combustion chamber as this would introduce more air for combustion. The unburnt air in combustion chamber serves as coolant. Therefore, the energy losses decrease as the temperature of the hot gases is decreased. This is due to high quantity of air mass flow which lowers the temperature of the hot gases.

Table 3. Results of energy performance analysis

\begin{tabular}{ll}
\hline Energy performance indicator & Value \\
\hline Installed rated power & $33.5 \mathrm{MW}$ \\
Energy loss of compressor & $0.71 \mathrm{MW}$ \\
Energy loss of combustion chamber & $11.35 \mathrm{MW}$ \\
Energy loss of turbine & $103.78 \mathrm{MW}$ \\
Total energy loss in the plant & $415.84 \mathrm{MW}$ \\
Network of turbine & $44.99 \mathrm{MW}$ \\
\% Energy loss of compressor & $1.50 \%$ \\
\% Energy loss of combustion chamber & $5.48 \%$ \\
$\%$ Energy loss of turbine & $31.98 \%$ \\
$\%$ Total energy loss in the plant & $38.96 \%$ \\
Energy input & $207.20 \mathrm{MW}$ \\
Thermal efficiency & $36.68 \%$ \\
\hline
\end{tabular}




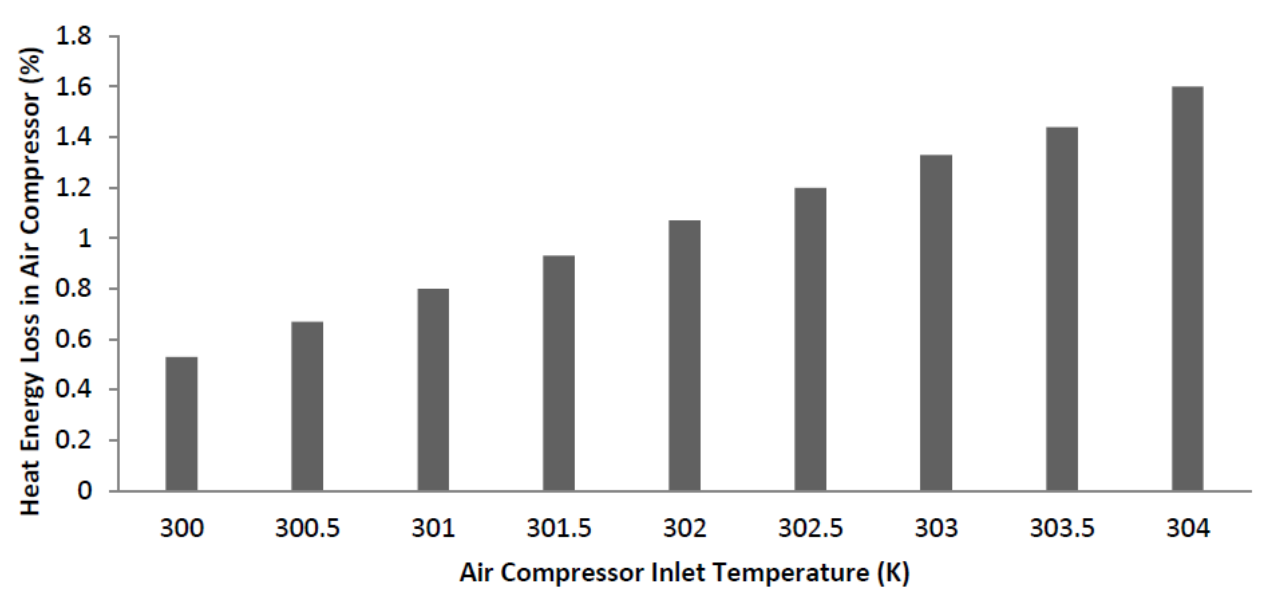

Fig. 14. Heat energy loss in air compressor (\%) Against air compressor inlet temperature (K)

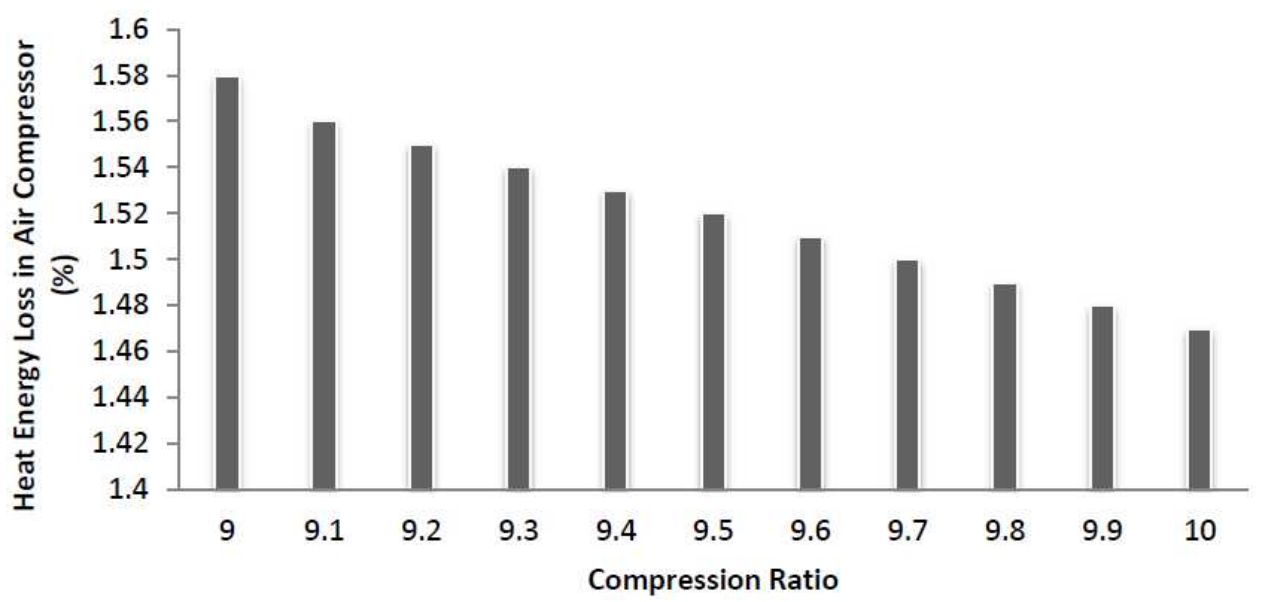

Fig. 15. Heat energy loss in air compressor (\%) against compression ratio

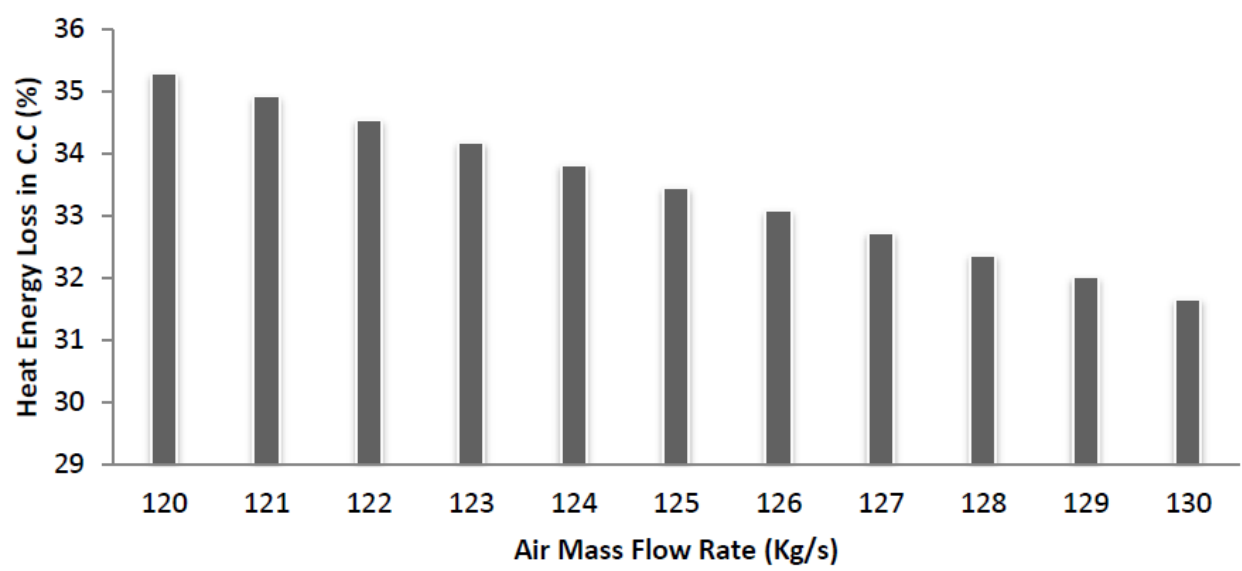

Fig. 16. Heat energy loss in combustion chamber (\%) against air mass flow rate $(\mathrm{kg} / \mathrm{s})$

From above discussion, it is obvious that gas turbine performance is affected by operating parameters. The magnitude of effects of these parameters on performance of gas turbine varies from power plant to power plant based on either technical deficiencies within the system or changes in ambient conditions. Arriving at a decision for plant performance improvement based on energetic performance may not 
be sufficient. For complex systems like gas turbine plant with multiple components, this may be misleading as quantifying actual losses in the different system components might not be accurately achieved. Using only energetic analysis for decision making is lopsided, since it does not reveal explicit presentation of plant performance. Therefore, the results obtained from energetic performance analysis should be considered with those of exergetic analysis allowing an improved understanding by quantifying the effect of irreversibility occurring in the plant and the location.

\section{Exergy Analysis}

In this study, the net exergy flow rates crossing the boundary of each component of the plant, together with the exergy destruction, exergy defect and exergy efficiency in each component are calculated and are presented in Table 4. The exergy analysis result shows that the highest percentage exergy destruction occurs in the Combustion Chamber (CC) $(90.71 \%)$ and turbine has the least exergy destruction rate $(1.76 \%)$. Hence, the $\mathrm{CC}$ is the major source of thermodynamic inefficiency in the plant considered in this study and this is due to the irreversibility associated with combustion and the large temperature difference between the air entering the CC and the flame temperature. These immense losses basically mean that a large amount of energy present in the fuel, with great capacity to generate useful work, is being wasted.

By comparing data in Table 3 and Table 4, the total plant losses for the plant is $38.96 \%$ for energetic consideration and $40.46 \%$ for exergetic cases. This shows that using only energetic analysis for decision making is in-balance as it does not reveal explicit presentation of plant performance. Therefore, the result obtained from energy analysis should be considered along with those from exergy analysis. This allows a better understanding by quantifying the effect of irreversibility occurring in the plant and the location of occurrence.

\section{Validation of Model}

The model developed in this study is validated by the actual data that were taken from the gas turbine power plant. Average parameters recorded within the period under review are set as baseline for comparison with the calculated results. The parameters considered in this study for the gas turbine engine during simulation are inlet temperature of the air compressor, the mass flow rate of fuel and turbine inlet temperature.

Table 5 presents results between the power plant data and simulation code. The comparison of simulation results and the actual data shows difference of between $1.17-5.04 \%$. The maximum difference is about $5.04 \%$ for mass flow rate of fuel while the minimum difference is about $1.17 \%$ for compressor outlet temperature. This validates the effectiveness of the developed simulation code to model the gas turbine power plant performance, as the results of the simulation values are close to the actual operating data of the plant considered in this study.

Table 4. Results of exergy analysis

\begin{tabular}{ll}
\hline Energy performance indicator & Value \\
\hline Fuel exergy flow rate & $220.53 \mathrm{MW}$ \\
Exergy destruction rate in compressor & $4.58 \mathrm{MW}$ \\
Exergy destruction rate in combustion chamber & $55.20 \mathrm{MW}$ \\
Exergy destruction rate in turbine & $1.07 \mathrm{MW}$ \\
Total exergy destruction rate in the plant & $60.85 \mathrm{MW}$ \\
\% Exergy destruction rate in compressor & $7.52 \%$ \\
\% Exergy destruction rate in combustion chamber & $90.71 \%$ \\
\% Exergy destruction rate in turbine & $1.76 \%$ \\
Exergy efficiency of compressor & $85.99 \%$ \\
Exergy efficiency of combustion chamber & $74.97 \%$ \\
Exergy efficiency of turbine & $98.56 \%$ \\
Overall exergetic efficiency & $19.06 \%$ \\
Exergetic performance coefficient & $1.45 \%$ \\
Efficiency defect of compressor & $14.01 \%$ \\
Efficiency defect of combustion chamber & $25.03 \%$ \\
Efficiency defect of turbine & $1.42 \%$ \\
Total efficiency defect of the plant & $40.46 \%$ \\
\hline
\end{tabular}

Table 5. Results between the power plant data and simulation code

\begin{tabular}{llccc}
\hline Parameter & Unit & Measured data & Simulation code & Difference (\%) \\
\hline $\mathrm{T}_{2}$ & $\mathrm{~K}$ & 622.31 & 629.59 & 1.17 \\
$\mathrm{~T}_{4}$ & $\mathrm{~K}$ & 750.00 & 775.02 & 3.34 \\
$\mathrm{~m}_{\mathrm{f}}$ & $\mathrm{kg} / \mathrm{s}$ & 2.58 & 2.45 & 5.04 \\
\hline
\end{tabular}




\section{Conclusion}

In this study, comprehensive thermodynamic modelling, energy and exergy analyses were performed for a gas turbine power plant in Nigeria. To achieve this aim, a simulation code was developed in MATLAB software program. In order to validate the simulation code, the results were compared with the actual data obtained from running the gas turbine power plant in Nigeria. The results showed a reasonably good agreement between simulation code results and experimental data obtained from the running of the gas turbine plant. The model reveals that the influence of operating parameters including the compression ratio, TIT and ambient temperature has significant effect on the performance of gas turbine power plant. The simulation results are summarized as follow:

- The thermal efficiency and power output decrease linearly with increase of ambient temperature

- The thermal efficiency and power output increase linearly at lower compression ratio with increase in TIT

- Heat supplied increases with TIT but decreases with compression ratio

- SFC increases with increase in ambient temperature but decreases with increase in compression ratio and TIT

- The TIT significantly affects the performance of gas turbine engine. It should be kept higher to minimize losses in the gas turbine system. Increasing the TIT increases the output power and thermal efficiency as a result of increasing the turbine work

Results of energy and exergy analyses show that turbine has the highest proportion of energy loss and CC is the most significant exergy destructor in the power plant. Thermal efficiency of the plant is as low as $36.68 \%$ while the total efficiency defect and overall exergetic efficiency of the power plant are 40.46 and $19.06 \%$, respectively.

\section{Acknowledgement}

The authors appreciate the Management of AES power plant for providing the data used in this study.

\section{Author's Contributions}

Sunday Olayinka Oyedepo: Contributed to conception, drafting the article, design, acquisition and analysis of data and interpretation of data.

Richard Olayiwola Fagbenle and Samuel Sunday Adefila: Coordinated drafting the article and reviewing it critically for significant intellectual content.

\section{Ethics}

This article is original and contains unpublished material. The corresponding author confirms that all of the other authors have read and approved the manuscript and no ethical issues involved.

\section{References}

Abam, F.I., I.U. Ugot and D.I. Igbong, 2011. Thermodynamic assessment of grid-based gas turbine power plants in Nigeria. J. Emerg. Trends Eng. Applied Sci., 2: 1026-1033.

Abam, D.P.S and N.N. Moses, 2011. Computer simulation of a gas turbine performance. Global J. Res. Eng., 11: 37-43.

Adrian, I. and L. Dorin, 2010. Thermodynamic analysis of gas turbine powered cogeneration systems. J. Scientific Indust. Res., 69: 548-553.

Ahmadi, P., I. Dincer and M.A. Rosen, 2011. Exergy, exergoeconomic and environmental analyses and evolutionary algorithm based multi-objective optimization of combined cycle power plants. Energy, 36: 5886-5898.

DOI: $10.1016 /$ j.energy.2011.08.034

Alcides, C.N., 1999. Assessment of novel power generation systems for biomass industry. $\mathrm{PhD}$ Thesis, Cranfield University.

Aljund, I.H., 2009. Energy and exergy analysis of a steam power plant in Jordan. Applied Thermal Eng., 29: $324-328$

Ameri, M., P. Ahmadi and S. Khanmohammadi, 2007. Exergy analysis of a $420 \mathrm{MW}$ combined cycle power plant. Int. J. Energy Res., 32: 175-183. DOI: $10.1002 /$ er.1351

Balkrishna, M.C., 2009. Energy and exergy analysis of a captive steam power plant. Proceedings of the International Conference of Energy and Environmental, (CEE' 09).

Avval, H.B., P. Ahmadi, A.R. Ghaffarizadeh and M.H. Saidi, 2011. Thermo-economic-environmental multiobjective optimization of a gas turbine power plant with preheater using evolutionary algorithm. Int. J. Energy Res., 35: 389-403.

DOI: $10.1002 /$ er. 1696

Bassily, A.M., 2001. Effects of evaporative inlet and aftercooling on the recuperated gas turbine cycle. Applied Thermal Eng., 21: 1875-1890. DOI: $10.1016 / \mathrm{S} 1359-4311(01) 00054-0$

Bejan, A., G. Tsatsaronis and M. Moran, 1996. Thermal Design and Optimization. 1st Edn., John Wiley and Sons, Inc. New York

Bilgen, E., 2000. Exergetic and engineering analyses of gas turbine based cogeneration systems. Energy, 25: 1215-1229.

DOI: $10.1016 / \mathrm{S} 0360-5442(00) 00041-4$ 
Chaker, M., C.B. Meher-Homji, T. Mee and A. Nicholson, 2003. Inlet fogging of gas turbine engines detailed climatic analysis of gas turbine evaporation cooling potential in the USA. J. Eng. Gas Turbine Power, 125: 300-309. DOI: 10.1115/1.1519266

Chen, Q., W. Han, J. Zheng, J. Sui and H. Jin, 2014. The exergy and energy level analysis of a combined cooling, heating and power system driven by a small scale gas turbine at off design condition. Applied Thermal Eng., 66: 590-602.

DOI: 10.1016/j.applthermaleng.2014.02.066

Eastop, T.D. and A. McConkey, 2009. Applied Thermodynamic for Engineering Technologists. $5^{\text {th }}$ Ed., Pearson Educational Ltd., India, pp: 290.

Ebadi, M.J. and M. Gorji-Bandpy, 2005. Exergetic analysis of gas turbine plants. Int. J. Exergy, 2: 3139. DOI: 10.1504/IJEX.2005.006431

Egware, H.O. and A.I. Obanor, 2013a. Exergy analysis of omotosho phase 1 gas thermal power plant. Int. J. Energy Power Eng., 2: 197-203. DOI: $10.11648 /$ j.ijepe.20130205.13

Egware, H.O. and A.I. Obanor, 2013b. Energy analysis of omotosho phase 1 gas thermal power plant. Int. J. Eng. Technol. Sci., 1: 206-217.

Erdem, H.A. and H.S. Sevilgen, 2006. Case study: Effect of ambient temperature on the electricity production and fuel consumption of a simple cycle gas turbine in Turkey. Applied Thermal Eng., 26: 230-236. DOI: $10.1016 /$ j.applthermaleng.2005.08.002

Fagbenle, R.L., A.B.C. Oguaka and O.T. Olakoyejo, 2007. A thermodynamic analysis of a Biogas-fired Integrated Gasification Steam Injected Gas Turbine (BIG/STIG) plant. Applied Thermal Eng., 27: 2220-2225.

Ganapathy, T., N. Alagumurthi, R.P. Gakkhar and K. Murugesan, 2009. Exergy analysis of operating lignite fired thermal power. J. Eng. Sci. Technol. Rev., 2: 123-130.

Gareta, R., L.M. Romeo and A. Gil, 2005. Economic optimization of gas turbine inlet air-cooling systems in combined cycle applications. Center for Power Plant Efficiency Research.

Ghazikhani, M, I. Khazaee and E. Abdekhodaie, 2014. Exergy analysis of gas turbine with air bottoming cycle. Energy, 72: 599-607. DOI: $10.1016 /$ j.energy.2014.05.085

Guinee, J.B., 2001. Life cycle assessment: An operational guide to the ISO standards. LCA in perspective; guide; operational annex to guide. The Netherlands: Centre for Environmental Science, Leiden University.

Habib, M.A., 1994. First- and second-law analysis of steam-turbine cogeneration systems. J. Eng. Gas Turbine Power, 116: 15-19. DOI: 10.1115/1.2906786

Hall, A.D., J.C. Stover and R.B. Breisch, 1994. Gas turbine inlet-air chilling at a cogeneration facility. ASHRE Transactions.
Ibrahim, T.K., M.M. Rahman and A.N. Alla, 2010. Study on the effective parameter of gas turbine model with intercooled compression process. Sci. Res. Essays, 5: 3760-3770.

Ibrahim-Bin, H., H.M. Masrul, Z.Y. Mohd and H.B. Mohd, 2001. Exergy-economics analysis of a thermal power plant. Proceedings of the 12th IAHR Cooling Tower and Heat Exchanger Symposium, (HES' 01), Sydney, Australia.

Ighodaro, O.O. and B.A. Aburime, 2011. Exergetic appraisal of delta IV power station, Ughelli. J. Emerg. Trends Eng. Applied Sci., 2: 216-218.

Jaber, Q.M., J.O. Jaber and M.A. Khawaldah, 2007. Assessment of power augmentation from gas turbine power plants using different inlet air cooling systems. Jordan J. Mech. Indust. Eng., 1: 7-15.

Kakaras, E., A. Doukelis and S. Karellas, 2004. Compressor intake-air cooling in gas turbine plants. Energy, 29: 2347-2358. DOI: $10.1016 /$ j.energy.2004.03.043

Kamal, N.A. and A.M. Zuhair, 2006. Enhancing gas turbine output through inlet air cooling. Sudan Eng. Society J., 52: 1-8.

Khaldi, F. and B. Adouane, 2011. Energy and exergy analysis of a gas turbine power plant in Algeria. Int. J. Exergy, 9: 399-413. 10.1504/IJEX.2011.043920

Khaliq, A. and S.C. Kaushik, 2004. Second-law based thermodynamic analysis of Brayton/Rankine combined power cycle with reheat. Applied Energy, 78: 179-197

Khaliq, A., K. Choudhary and I. Dincer, 2009. Exergy analysis of a gas turbine trigeneration system using the Brayton refrigeration cycle for inlet air cooling. J. Power Energy, 224: 449-461. DOI: $10.1243 / 09576509 J P E 897$

Kopac, M. and A. Hilalci, 2007. Effect of ambient temperature on the efficiency of the regenerative and reheat Çatalağzı power plant in Turkey. Applied Thermal Eng., 27: 1377-1385. DOI: $10.1016 /$ j.applthermaleng.2006.10.029

Kotas, T.J., 1995. The Exergy Method of Thermal Plant Analysis. 1st Edn., Krieger Publishing Company, Malabar, Florida, ISBN-10: 0894649418, pp: 328.

Kreith, F. and Y.D. Goswanni, 2005. The CRC Handbook of Mechanical Engineering. 2nd Edn., CRC Press, Boca Raton, ISBN10: 0849308666, pp: 2688.

Kurt, H., Z. Recebli and E. Gredik, 2009. Performance analysis of open cycle gas turbines. Int. J. Energy Res., 33: 285-294. DOI: 10.1002/er. 1472

Lior, N. and N. Zhang, 2007. Energy, exergy and Second Law performance criteria. Energy, 32: 281-296. DOI: 10.1016/j.energy.2006.01.019

Mahmoudi, S.M, V. Zare, F. Ranjbar and L. Farshi, 2009. Energy and exergy analysis of simple and regenerative gas turbines inlet air cooling using absorption refrigeration. J. Applied Sci., 9: 2399-2407. DOI: $10.3923 /$ jas.2009.2399.2407 
Martin, A., M.A. Prayitno and I.K. Romy, 2016. Exergy analysis of gas turbine power plant $20 \mathrm{MW}$ in Pekanbaru-Indonesia. Int. J. Technol., 5: 921-927. DOI: 10.14716/ijtech.v7i5.1329

Mirandola, A., A. Stoppato and S. Tonon, 2000. An integrated approach to the assessment of energy conversion plants. Int. J. Applied Thermodynam., 3: 111-119.

Mozafari, A., A. Ahmadi and M.A. Ehyaei, 2010. Optimisation of micro gas turbine by exergy, economic and environmental (3E) analysis. Int. J. Exergy, 7: 1-19. DOI: 10.1504/IJEX.2010.029611

Nag, P.K., 2008. Power Plant Engineering. 1st Edn., Tata McGraw-Hill Publishing Company Limited, New Delhi, ISBN-10: 0070648158, pp: 950.

Obodeh, O. and P.E. Ugwuoke, 2013. Time-dependent exergy analysis of a $120 \mathrm{MW}$ steam turbine unit of sapele power plant. Am. J. Electr. Power Energy Syst., 2: 129-136. DOI: 10.11648/j.epes.20130206.12

Ofodu, J.C. and D.P.S. Abam, 2002. Exergy analysis of afam thermal power plant. NSE Tech. Trans., 37: 14-28.

Oh, S.D., H. Pang, S. Kim and H. Kwak, 1996. Exergy analysis for a gas turbine cogeneration system. J. Eng. Gas Turbine Power, 118: 782-791. DOI: $10.1115 / 1.2816994$

Osman, A.H., A.A. Hamed and A.A. Holayil, 2006. Thermoeconomic analysis of a power/water cogeneration plant. Energy, 31: 2699-2709.

Oyedepo, S.O. and O. Kilanko, 2014. Thermodynamic analysis of a gas turbine power plant modeled with an evaporative cooler. Int. J. Thermodynam., 17: 14-20.

Oyedepo, S.O., 2014. Thermodynamic performance analysis of selected gas turbine power plants in Nigeria. Ph.D Thesis, Covenant University, Ota, Nigeria.

Rahman, M.M., T.K. Ibrahim, M.Y. Taib, M.M. Noor K. Kadirgama and R.A Bakar, 2010. Thermal analysis of open-cycle regenerator gas-turbine powerplant. WASET, 68: 94-99

Rahman, M.M., T.K. Ibrahim, K. Kadirgama, R. Mamat and R.A. Bakar, 2011a. Influence of operation conditions and ambient temperature on performance of gas turbine power plant. Adv. Mater. Res., 189-193: 3007-3013.

DOI: 10.4028/www.scientific.net/AMR.189-193.3007

Rahman, M.M., T.K. Ibrahim and A.N. Abdalla, 2011 b. Thermodynamic performance analysis of gasturbine power-plant. Int. J. Phys. Sci., 6: 3539-3550. DOI: $10.5897 / \mathrm{IJPS} 11.272$

Rajkumar, S.C. and K. Ashok, 2009. Energy and exergy analysis of non- reheat thermal power plant. Proceedings of International Conference of Energy and Environmental, (CEE' 09).

Rajput, R.K., 2007. Engineering thermodynamics (S.I Units). Laxmi Publications (P) LTD 113, Golden House, Daryaganj, New Delhi-110002.
Ray, T.K., R. Ganguly and A. Gupta, 2007. Exergy analysis for performance optimization of a steam turbine cycle. Proceedings of the IEEE Power Engineering Society Conference and Exposition in Africa, IEEE Xplore Press, Jul. 16-20, pp: 1-8. DOI: 10.1109/PESAFR.2007.4498116

Reddy, V.S., S.C. Kaushik and N.L. Panwar, 2013. Review on power generation scenario of India. Renewable Sustainable Energy Rev., 18: 43-48. DOI: $10.1016 /$ j.rser.2012.10.005

Sadrameli, S.M. and D.Y. Goswami, 2007. Optimum operating conditions for a combined power and cooling thermodynamic cycle. Applied Energy, 84: 254-265. DOI: 10.1016/j.apenergy.2006.08.003

Sanjay, O., A. Muku and Y. Rajay, 2009. Energy and exergy analysis of brayton-diesel cycle. Proceedings of the World Congresson Engineering, Jul. 1-3, London, pp: 1-6.

Soltani, S., S.M.S. Mahmoudi, M.A. Rosen and T. Morosuk, 2015. Exergy analysis of a gas-turbine cycle with fogging inlet cooling. Int. J. Exergy, 18: 104-127. DOI: 10.1504/IJEX.2015.072062

Suresh, M.V.J.J., K.S. Reddy and A.K. Kolar, 2006a. Energy and exergy analysis of thermal power plants based on advanced steam parameters. Adv. Energy Res.

Suresh, M.V.J.J., K. S. Reddy and A.K Kolar, 2006b. Energy and exergy based thermodynamic analysis of a 62.5 MWe coal-based thermal power plant-a case study. Proceedings of the International Conference on Energy and Environment, Aug. 28-30, Selangor, Malaysia, pp: 24-24.

Tahouni, N., B. Jabbari and M.H. Panjeshahi, 2012. Optimal design of a cogeneration system in a Kraft process using genetic algorithm. Chem. Eng. Trans., 29: 19-24.

\section{Nomenclature}

\section{Symbols}

$c_{p}$ : Specific heat at constant pressure, $[\mathrm{kJ} / \mathrm{kg}]$

$E$ : Exergy rate, $[\mathrm{kW}]$

$\dot{E}_{L}$ : Exergy loss rate

$\dot{E}_{D}$ : Exergy destruction rate

$\dot{m}$ : Mass flow, $[\mathrm{kg} / \mathrm{s}]$

$P$ : Power output, [kW]

$P e:$ Potential energy $[\mathrm{kJ}]$

$r_{p}$ : Pressure compression ratio

$R:$ Gas constant $[\mathrm{kJ} / \mathrm{mol}-\mathrm{K}]$

$y_{D}$ : Exergy destruction rate ratio

\section{Greek Symbols}

$\gamma: \quad$ Adiabatic index

$\Delta p_{c c}$ : Pressure drop in combustion chamber (bar)

$\eta_{c}$ : Isentropic efficiency of compressor 
$\eta_{T}: \quad$ Isentropic efficiency of turbine

$\eta_{t h}: \quad$ Thermal efficiency

$\epsilon$ : $\quad$ Exergetic efficiency

$\emptyset: \quad$ Rational efficiency

$\delta$ : $\quad$ Component efficiency defect

$\psi: \quad$ Overall exergetic efficiency

$\xi$ : $\quad$ Exergetic performance coefficient

\section{Subscripts}

$i$ : $\quad$ Inlet

$e$ : $\quad$ Exit or outlet

$p$ : Pressure

a: Air

pg: Combustion product

$f:$ Fuel

T: Turbine

$c c$ : Combustion chamber

th: Thermal

sys: System

0: Ambient

$c v$ : Control volume

$D$ : Destruction

gen: Generation

ac: Air compressor

$g t$ : Gas turbine

$k$ : Component

Superscripts

tot: Total

PH: Physical

$\mathrm{KN}$ : Kinetic

PT: Potential

CHE: Chemical

T: Thermal

P: Mechanical 